\title{
Supporting Information: Enabling Flow-based Kinetic Off-rate Selections using a Microfluidic Enrichment Device (MFED)
}

William E. Evenson, $\$$ Wan-Zhen Sophie Lin, $\$$ Kenmond Pang, Alexander T. Czaja, Farzad Jalali-Yazdi, Terry T. Takahashi, Noah Malmstadt, ${ }^{*}$ Richard W. Roberts*

University of Southern California, Los Angeles, California, USA

Table of Content

Supplementary Figures

Figure S1: Manual off-rate determination of Pep2

Figure S2: Dilution and PCR of a mixture of E1 and Pep2 PCR products

Figure S3: Determinization of molar ratio from band intensity ratio using a standard curve

Supplementary Materials and Methods

MFED Design and Fabrication

Ligand Preparation

Target Protein

Radioactive BindingsAssays

Selection

PCR

\$ W.E.E. and W.S.L. contributed equally to this work.

*Noah Malmstadt, Email: malmstad@usc.edu

*Richard W. Roberts, Email: richrob@usc.edu 


\section{Supplementary Figures}

Figure S1. Radiolabeled manual competitor-based off-rate measurement of Pep2. Beads containing Bcl$\mathrm{x}_{\mathrm{L}}$ were exposed to radiolabeled Pep2, washed, and resuspended with $100 \mathrm{X}$ free $\mathrm{Bcl}-\mathrm{x}_{\mathrm{L}}$. Timepoints were taken after the resuspension in free Bcl- $\mathrm{x}_{\mathrm{L}}$ and the percent of Pep2 retained on the beads was recorded and normalized such that the initial binding percentage was $100 \%$. The curve was fit as a single exponential decay using a nonlinear fit in Prism ${ }^{\circledR}$. The $\mathrm{k}_{\text {off }}$ was $1.1 \pm 0.2 \mathrm{sec}^{-1}$, and a minimum percent bound of $19 \%$.

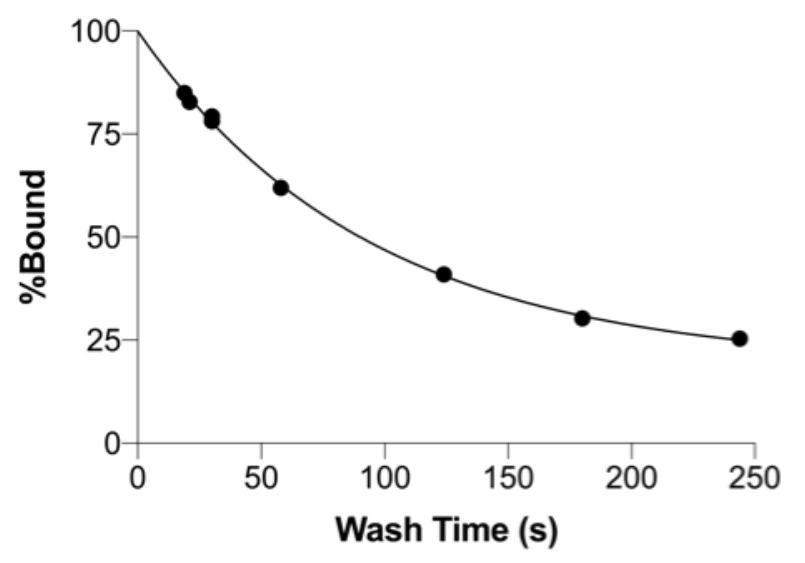

Figure S2. Dilution and PCR of 1:1 mixture of E1 and Pep2 PCR products. The gel image indicates that after 7 cycles, the band intensities for E1 and Pep2 are comparable, and this continues to be true through 22 cycles. This implies that there is minimal PCR bias.

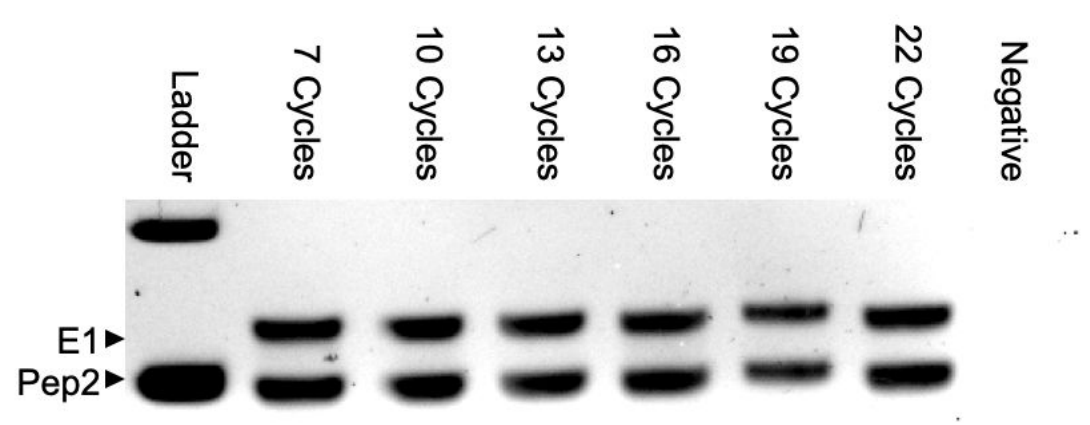


Figure S3. Determination of molar ratio from band intensity ratio using a standard curve. Defined mixtures of ligated E1 and Pep2 were mixed and reverse transcribed. That sample was then amplified by PCR and run on agarose gels (A, standard). The band intensity ratios were calculated using Image Studio Lite ${ }^{\circledR}$ to build a standard curve (B). PCR was performed on RT'ed fusions before and after selection were also run on agarose gels (A, RT and C, Manual \& MFED). The band intensity ratios were calculated using Image Studio Lite ${ }^{\circledR}(\mathrm{D})$ and then converted to molar ratios using a linearization between surrounding points in the standard curve (Figure 4B).

(A)

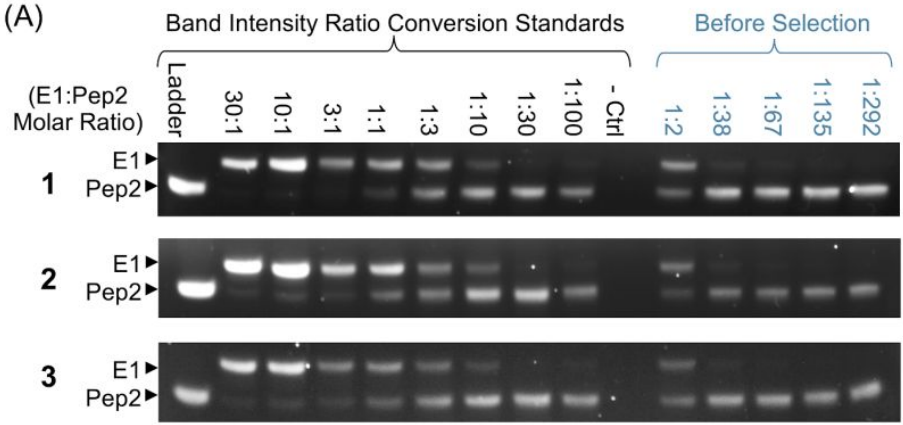

(C)

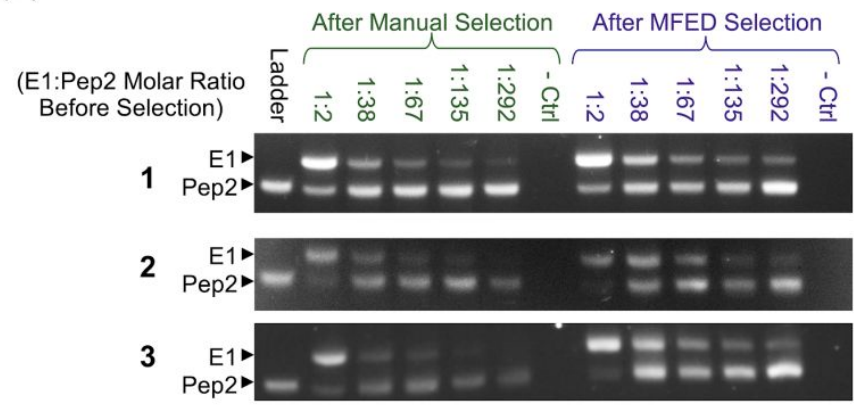

(B)

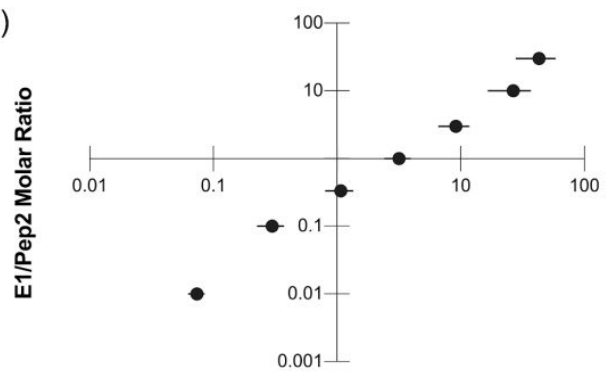

E1/Pep2 Band Intensity Ratio

(D)

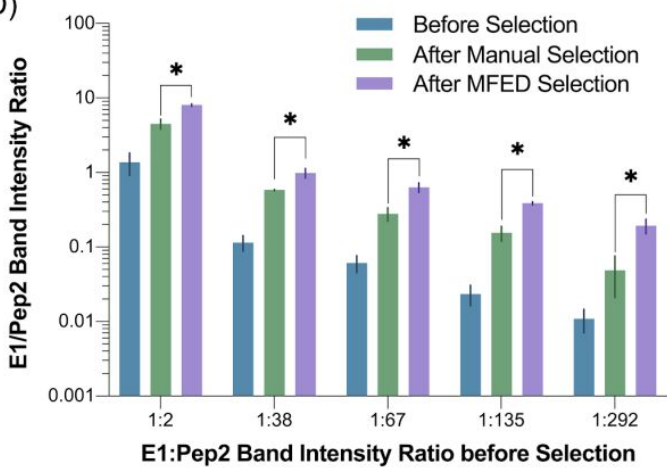




\section{Supplementary Materials and Methods MFED Design and Fabrication}

The MFED consisted of a set of 3D printed parts that housed a polyether ether ketone (PEEK, outer ring material: polychlorotrifluoroethylene, PCTFE) frit with $10 \mu \mathrm{m}$ pore size (IDEX Health \& Science). The 3D printed parts of the microfluidic device were fabricated using a benchtop digital light processing stereolithography (DLP-SL) printer (Asiga Max X27 UV, Asiga, Australia) with a clear methacrylate-based resin (Pro3dure GR-1 Clear, Pro3dure Medical, Germany). The MFED connected two segments of microfluidic polytetrafluorethylene (PTFE) tubing (1/16" outer diameter and 1/32" inner diameter) to both sides of the frit (Figure 1) to facilitate continuous flow across the frit. In order to minimize interactions with the 3D printed parts, the MFED only allowed the liquid to come in contact with the tubing and the frit. The frit was used to immobilize agarose beads (50-150 um, Thermo) on one side while allowing free ligands to flow past the bead bed.

\section{Ligand Preparation}

We used two previously identified Bcl- $\mathrm{x}_{\mathrm{L}}$ ligands: $\mathrm{E} 1$ (amino acid sequence MIETITIYNYKKAADHFSMSM) and Pep2 (MWRWKMIADQL). ${ }^{1,2}$ E1 was previously characterized to be a high-affinity ligand with a binding constant $\left(\mathrm{K}_{\mathrm{D}}\right)$ of $20-40 \mathrm{pM}$ and an off-rate constant of $7.4 \times 10^{-6} \mathrm{~s}^{-}$

1. Pep2 was previously characterized to be a lower affinity ligand when compared to E1, with a $\mathrm{K}_{\mathrm{D}}$ of approximately $65 \mathrm{nM}$. Both clones were amplified by PCR with Taq polymerase using the same primers $\left(5^{\prime}=\right.$ TAATACGACTCACTATAGGGACAATTACTATTTACAATTACA and 3 ' = GCTGGAGCCACTGCCAGATCCCA) and then transcribed in vitro using T7 RNA polymerase. ${ }^{3}$ Upon completion, transcription was stopped by adding $10 \%(\mathrm{v} / \mathrm{v})$ of $500 \mathrm{mM}$ EDTA $(\mathrm{pH}=8)$ and the mixture was buffer exchanged into Milli-Q water using 30K Amicon filters (EMD Millipore). The mRNA was ligated to F30P (phosphate-dA21-[C9]3-dAdCdCP, synthesized at the Keck Oligo Facility at Yale using reagents from Glen Research) using T4 DNA ligase. The ligated mRNA was purified by urea-PAGE and resuspended in Milli-Q water. Subsequently, the clones were translated with $400 \mathrm{nM}$ ligated mRNA in 20 
$\mathrm{mM}$ HEPES-KOH $(\mathrm{pH}=7.6), 100 \mathrm{mM} \mathrm{KOAc}, 0.5 \mathrm{mM} \mathrm{Mg}(\mathrm{OAc})_{2}, 8 \mathrm{mM}$ creatine phosphate, $2 \mathrm{mM}$ DTT, $25 \mathrm{uM}$ each amino acid, and 40\% rabbit reticulocyte lysate (Green Hectares; prepared according to the method of Jackson and Hunt ${ }^{4}$. The translation reactions were incubated at $30{ }^{\circ} \mathrm{C}$ for $1 \mathrm{hr}$, followed by fusion formation with an addition of $250 \mathrm{mM} \mathrm{KCl}$ and $30 \mathrm{mM} \mathrm{MgCl}_{2}$ while incubating at room temperature for 5 minutes. For the translation of radiolabeled peptides, unlabeled methionine was replaced with ${ }^{35} \mathrm{~S}$ methionine (Perkin Elmer).

After translation, the fusions were purified using poly $\mathrm{T}$ agarose beads. Biotinylated poly $\mathrm{T}$ (IDT) was immobilized on Streptavidin agarose beads (Thermo). $500 \mu \mathrm{L}$ of $100 \mathrm{mM}$ HEPES-KOH (pH=8), $1 \mathrm{M} \mathrm{NaCl}$, $0.2 \%(\mathrm{v} / \mathrm{v})$ Triton-X-100 with poly $\mathrm{T}$ beads was added to $100 \mu \mathrm{L}$ of translation and incubated at $4{ }^{\circ} \mathrm{C}$ for 1 hr with rotation. Subsequently, the beads were washed on a Spin-X filter (Corning) and eluted with MilliQ water. The eluted fusions were reverse transcribed with Superscript IV in $50 \mathrm{mM}$ Tris- $\mathrm{HCl}(\mathrm{pH}=8.3), 75$ $\mathrm{mM} \mathrm{KCl}, 3 \mathrm{mM} \mathrm{MgCl} 2,10 \mathrm{mM}$ DTT, $500 \mathrm{uM}$ each dNTP, and $1 \mathrm{mM}$ 3' primer. The reaction was incubated at $42{ }^{\circ} \mathrm{C}$ for 1 hour to facilitate reverse transcription, then further incubated at $65^{\circ} \mathrm{C}$ for 15 min to inactivate Superscript IV. The resulting reverse-transcribed fusions (RT'd fusions) were kept in the fridge until use in radioactive binding assays or selection.

\section{Target Protein}

Bcl- $\mathrm{x}_{\mathrm{L}}$ was gifted from Terry Takahashi and Farzad Jalali-Yazdi², who obtained the gene for the first 209 amino acids of Bcl- $\mathrm{x}_{\mathrm{L}}$ (Clone HsCD00004711; Dana Farber/Harvard Cancer Center DNA Resource Core). The gene was PCR amplified with Pfusion polymerase and was added to an N-terminal avitag (AGGLNDIFEAQKIEWHEGG) for in vivo biotinylation. The product was cloned into pET24a and expressed at $37^{\circ} \mathrm{C}$ overnight in BL21(DE3) cells using an auto-induction media ${ }^{5}$. The cells were lysed with Bper (Pierce) and purified on Ni-NTA resin on an FPLC (Bio-Rad). The fractions were combined, concentrated, and then reacted with BirA biotin ligase to tag the protein with biotin. The protein was buffer exchanged into $1 \mathrm{X}$ PBS, frozen in liquid nitrogen, and stored at $-80^{\circ} \mathrm{C}$. 


\section{Radioactive Binding Assays}

100 pmol of biotinylated $\mathrm{Bcl}-\mathrm{x}_{\mathrm{L}}$ were coupled to $5 \mu \mathrm{L}$ of neutravidin agarose beads (Thermo Fisher Scientific, USA) in a binding buffer at $4{ }^{\circ} \mathrm{C}$ for 1 hour. The binding buffer consisted of $1 \mathrm{X}$ PBS with $0.1 \%$ (w/w) BSA and $0.01 \%(w / w)$ yeast tRNA. Subsequently, the beads were washed and blocked in blocking buffer (binding buffer $+10 \mathrm{uM}$ biotin). The MFED was positioned vertically while the beads were withdrawn into the device using a syringe pump (Next Advance pump, BD syringe) through the inlet of the device at a flow rate of $500 \mu \mathrm{L} / \mathrm{min}$, packing the beads against the frit (Figure 1A). Roughly 100,000 counts of radiolabeled RT'd fusions of E1 or Pep2 were then diluted in a 1:3 ratio in the blocking buffer and withdrawn into the MFED through the inlet at various flow rates to bind the immobilized $\mathrm{Bcl}-\mathrm{x}_{\mathrm{L}}$ in the device. The flow-through was collected and the radioactive counts were recorded. After binding, blocking buffer was infused through the inlet of the device to wash the beads at various flow rates and each wash was collected at the outlet for radioactive counting. The beads were removed with $1500 \mu \mathrm{L} / \mathrm{min}$ blocking buffer in the opposite direction. The beads were collected and counted on a scintillation counter (Beckman LS 6500).

\section{Selection}

Selection on the MFED was performed in the same manner as the radioactive binding assays with a few exceptions: 1) the flow-through and washes were not collected, and 2) the beads were evacuated with a PCR solution instead of blocking buffer in order to PCR amplify the bound ligands afterwards. In addition to MFED-based selection, control trials were performed on Spin-X columns. In the control trials, the ligands were allowed to bind the beads in $500 \mu \mathrm{L}$ of binding buffer for $1 \mathrm{hr}$ at room temperature, and then washed 3 times on a Spin-X column with binding buffer.

\section{PCR}

After selection, the beads resuspended in a PCR reaction solution were amplified using standard thermocycling techniques. After 9 cycles, the PCR products were run on an agarose gel to determine the 
presence of visible bands. If no bands were visible, the reaction was run for an additional 3 cycles. If a weak band was observed, 1 to 2 additional cycles were performed. After additional cycles, the PCR products were again run on an agarose gel to determine if additional cycles were required to attain visible bands. After selection, samples were amplified between 12 and 16 cycles in order to observe bands.

\section{Band Intensity Analysis}

The E1 PCR product was 126 base pairs (bp) and the Pep2 product was $96 \mathrm{bp}$. The intensities of each band in a $2 \%$ agarose gel were observed to determine relative abundances of each clone before and after selection. The band intensity ratios of E1 and Pep2 were obtained using Image Studio Lite ${ }^{\circledR}$ and the corresponding molar ratios were determined using a calibration curve which correlates molar ratios and band intensity ratios.

\section{References}

1. Jalali-Yazdi, F.; Corbin, J. M.; Takahashi, T. T.; Roberts, R. W., Robust, Quantitative Analysis of Proteins using Peptide Immunoreagents, in Vitro Translation, and an Ultrasensitive Acoustic Resonant Sensor. Analytical chemistry 2014, 86 (10), 4715-4722.

2. Jalali-Yazdi, F.; Huong Lai, L.; Takahashi, T. T.; Roberts, R. W., High-Throughput Measurement of Binding Kinetics by mRNA Display and Next-Generation Sequencing. Angewandte Chemie International Edition 2016, 55 (12), 4007-4010.

3. Liu, R.; Barrick, J. E.; Szostak, J. W.; Roberts, R. W., [19] Optimized synthesis of RNA-protein fusions for in vitro protein selection. 2000.

4. Jackson, R. J.; Hunt, T., [4] Preparation and use of nuclease-treated rabbit reticulocyte lysates for the translation of eukaryotic messenger RNA. In Methods in enzymology, Elsevier: 1983; Vol. 96, pp 5074.

5. Studier, F. W., Protein production by auto-induction in high-density shaking cultures. Protein expression and purification 2005, 41 (1), 207-234. 